\title{
Prognosis Factors in Patients with Spinal Cord Trauma
}

\section{Fatores de prognóstico em pacientes com trauma raquimedular}

\author{
Dionei Freitas de Morais ${ }^{1}$ João Simão de Melo Neto ${ }^{2}$ Lucas Crociati Meguins ${ }^{3}$ \\ Antonio Ronaldo Spotti ${ }^{3}$ Waldir Antonio Tognola ${ }^{4}$
}

1 Department of Neurological Science, Faculdade de Medicina de São José do Rio Preto (FAMERP), São José do Rio Preto, São Paulo, Brazil

2 Faculdade de Medicina de Marília (FAMEMA), Marília, São Paulo, Brazil

Address for correspondence Dionei Freitas de Morais, PhD, Department of Neurosurgery, Street Jose Munia, 4850, Jardim do Sul, São José do Rio Preto, São Paulo, Brazil CEP 5090-500

3 Faculdade de Medicina de São José do Rio Preto (FAMERP), São José (e-mail: dionei@cerebroecoluna.com.br).

4 MD, Instituto de Neurologia Rio Preto, São José do Rio Preto, São Paulo, Brazil

Arq Bras Neurocir 2015;34:97-102.

\begin{abstract}
Keywords

- traumatology

- complications

- mortality

\section{Resumo}

Palavras-chave

- traumatologia

- complicações

- mortalidade

Objective Analyze the predictors of prognosis in patients with spinal cord trauma (SCT) in a tertiary hospital.

Method Study prospective with 321 patients. The analysis focused on patient-related data, cause of accident, anatomical distribution, neurologic status, associated injuries, length of hospital stay, and in-hospital complications/mortality.

Results The SCT was more common in men, but women older than 50 years presented a higher risk than men of the same age. Automobile accidents, motorcycle accidents, and gunshots resulted in more injuries associated. The cervical spine involvement was directly related to an increase in the number of associated injuries, complications, and mortality. Already, the neurologic status ASIA-A was associated with an increase in the number of complications, length of stay, and mortality.

Conclusion The predictive factors of prognosis in these patients included age, sex, cause of injury, anatomic distribution, and neurologic status.

Objetivo Analisar os preditores de prognóstico em pacientes vítimas de trauma raquimedular (TRM) em um hospital terciário.

Método Estudo prospectivo com 321 pacientes. A análise foi direcionada aos dados relacionados aos pacientes, causa do acidente, distribuição anatômica, status neurológico, lesões associadas, tempo de permanência hospitalar e complicações e mortalidade no hospital.

Resultados O TRM foi mais comum em homens, mas mulheres com idade superior a 50 anos apresentaram mais risco que homens da mesma faixa etária. Ferimento por arma de fogo, acidentes automobilísticos e de motocicleta resultaram em maior número de lesões associadas. O trauma na coluna cervical foi diretamente relacionado
\end{abstract}

received

May 28, 2014

accepted

March 31, 2015
DOI http://dx.doi.org/

$10.1055 / \mathrm{s}-0035-1554899$.

ISSN 0103-5355.
Copyright ( $\odot 2015$ by Thieme Publicações License terms

Ltda, Rio de Janeiro, Brazil

(c) (1) $\ominus$ (요 
a um aumento no número de lesões associadas, complicações e mortalidade. Além disso, o status neurológico ASIA-A foi associado com um aumento no número de complicações, tempo de permanência e mortalidade.

Conclusão Os fatores preditivos de prognóstico nesses pacientes foram: idade, sexo, causa da lesão, distribuição anatômica e status neurológico.

\section{Introduction}

Traumatic injuries are an important cause of death among young people, and although spinal cord traumas (SCTs) represent only a minority of injuries suffered by all trauma patients, their social, financial, and familial influences are extremely relevant and often more significant than those of other injuries. $^{1-3}$

The SCT is injury that results in the sequel sensory, motor, and autonomic functions. ${ }^{4}$ The diagnostic precision is very important to the success of the treatment. ${ }^{5}$ Additionally, the presence of associated lesion, ${ }^{6-8}$ neurologic severity of the injury, and spinal segment may contribute negatively to prognosis. Therefore, it becomes relevant to carry out a more thorough and comprehensive study in order to determine the factors that can really influence the prognosis of patients with SCT.

This study aims to analyze the prognostic factors in patients with SCT on a tertiary hospital.

\section{Methods}

A total of 321 patients with SCT were studied during the period from January 2008 to June 2012. All patients were admitted in the emergency department of the Hospital de Base, in São Jose do Rio Preto/Brazil. The data extracted from the original database for this study included general patients characteristics, mechanisms of trauma, level and regions of SCT, and final disposition/outcome, especially regarding death. The analysis focused on patient-related data (age at trauma incident, sex), cause of accident (fall, traffic accident involving car, motorcycle, bicycle, or pedestrian; sports; miscellaneous), anatomical distribution (CO-C2; C3-C7; T1-T10; T11-L2; L3-S1), neurologic status (American Spine Injury Association scale [ASIA]), ${ }^{9}$ associated injuries, length of hospital stay, and in-hospital complications/mortality.

The tests used for statistical analysis were Dunn's test for length of stay and chi-square test for assessing the association between variables and relative risk, being considered $p<0.05$, as statistically significant.

The research was approved by the research ethics committee of the Faculty of Medicine from São José do Rio Preto (FAMERP), protocol 4823/2009. Subjects signed the informed consent form. When patient had the worst diagnosis or changes in level of consciousness, the written informed consent was given by a close relative. The study was conducted in compliance with the Declaration of Helsinki.

\section{Results}

\section{Patient-Related Data}

The study group (total of 321 patients) consisted of 231 males (72\%) and 90 females (28\%) patients. The overall maleto-female ratio was 2.6:1. The mean age of patients with spinal fractures was 42.7 years, ranging from 5 to 93 years. The highest rate of SCT was observed in the patients aged 21 to 30 years; however, women older than 50 years had a risk of 1.43 ( $p=0.04$, chi-square test) more often than men in the same age group. The distribution of SCT according to patient age and sex is shown in - Fig. 1 .

\section{Etiology of Injury}

The etiology of SCT and their frequencies along with the neurologic status, clinical complications, associated lesions, and anatomical distribution are summarized in - Table 1. Automobile accidents were the most common etiology of trauma with 133 patients (41\%), followed by accidental falls with 89 (28\%) patients. Automobile accidents were also involved most frequently with neurologic deficits revealing 23 patients (7\%) ASIA-A on admission and $25(8 \%)$ patients $A S I A-B / C / D$; accidental falls were second most frequent with 14 (4\%) patients ASIA-A on admission and 21 (7\%) patients ASIA-B/C/D; and motorcyclists were the third with 13 (4\%) patients ASIA-A and 13 (4\%) patients ASIA-B/C/D.

Only the etiologies, automobile accidents, motorcycle accidents, and gunshots were significantly associated with a greater number of associated lesions (chi-square test, $p<0.001$, with $95 \%$ of total dependence). No other significant association was found.

\section{Anatomical Distribution}

The 321 patients in our study population sustained 559 injuries. These injuries were categorized into five anatomical regions: high cervical (CO-C2), low cervical (C3-C7), thoracic (T1-T10), thoracolumbar transition (T11-L2), and lumbarsacral (L3-S1). The low cervical region was the most common segment of spinal fracture with 121 patients (38\%), followed by thoracolumbar transition with 80 patients $(25 \%)$, thoracic with 41 patients (13\%), high cervical with 28 patients (7.2\%), and lumbar-sacral with 16 patients (5\%). Of the 321 patients with SCT, 35 (11\%) had multiple injuries involving different areas of the spine (-Table 2 ).

An interesting relation between the etiology of trauma and the fracture region was found in the patients who suffered spinal fractures. Traffic accidents, motorcycle 


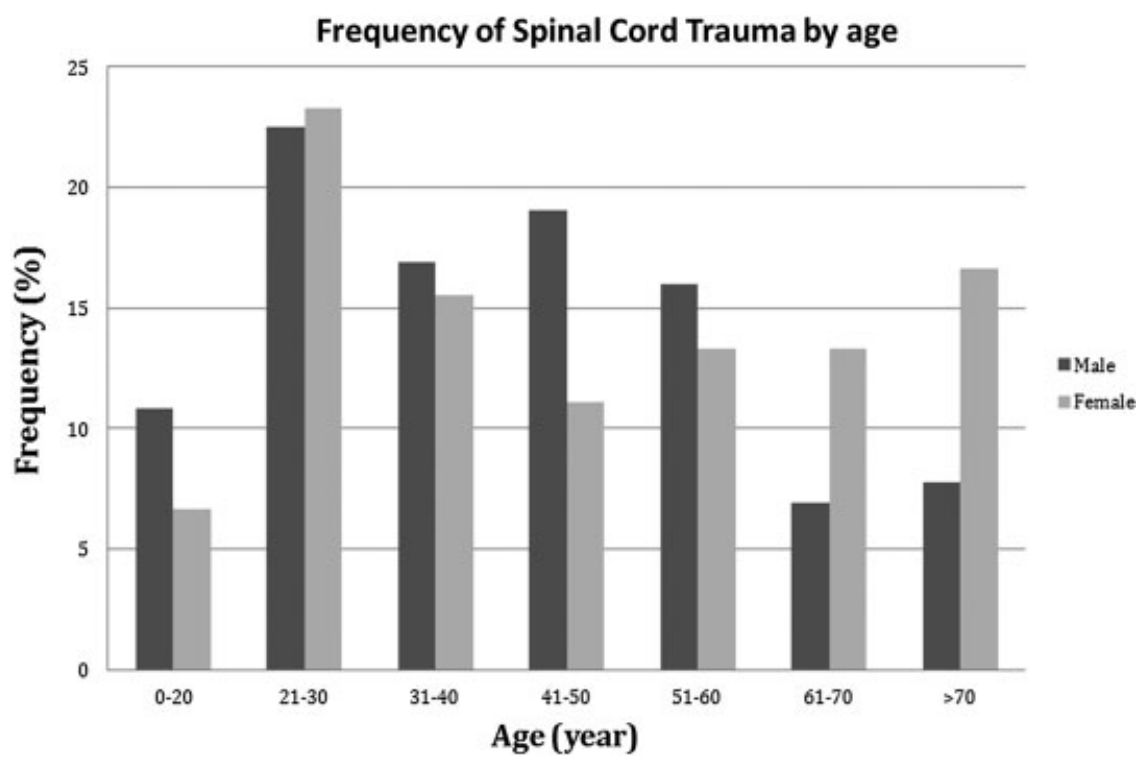

Fig. 1 Age and sex distribution.

accidents, and sports injuries resulted more often in low cervical spine injuries. On the other hand, accidental falls resulted in thoracolumbar transitional region fractures more often than in other segments of the spine ( - Table 1$)$. The most common level of observed spinal fracture was C6 (14.3\%), followed by C5 (12.9\%) and L1 (9.3\%).

Evaluating the association between the anatomical distribution of the SCT and the number of associated injuries with the chi-square test, our study demonstrated that with higher level of the fracture along the spine, the number of associated injuries increases $(p=0.001)$, as shown - Fig. 2A, with $80 \%$ of the total dependence explained. Using the same study, we found an association ( $p=0.0004$, chi-square test) with the anatomical distribution of the lesion with the number of complications. The dependence diagram with $97 \%$ of the explanation of the total dependence showed that $60 \%$ of the dependence comes from a higher number of complications as higher level of SCT (- Fig. 2B).

Patients with cervical spine injury had significantly increased neurologic deficit, clinical complications, and injuries associated with a risk of death 2.4 times more compared with other segments of the spine ( $p<0.05$, chi-square test).

\section{Neurologic Status}

Using the ASIA classification system, theses spinal cord injuries were divided into three groups of patients: ASIA-A (patients exhibiting complete motor and sensitive deficit), ASIA-B/C/D (patients exhibiting incomplete motor or sensitive deficit), and ASIA-E (patients exhibiting no motor or sensitive deficit).

The total of 143 patients suffered SCT with neurologic deficit ( - Table 3 ).The most frequent fractured anatomical region associated with complete and incomplete motor and sensorial deficit (ASIA-A and ASIA-B/C/D) was the low cervical region.

Using the chi-square test, the present study founded a significant association between the neurologic status and the number of complications (dependence diagram with $97 \%$ of resolution). We demonstrated that the number of clinical complications rises progressively while the neurologic status of patients with spinal injuries gets worst $(p<0.001)$ ( - Fig. 3).

Patients with ASIA-A showed $57 \%$ of clinical complications, 4.24 higher risk of mortality $(p=0.0001)$, and length of stay (21.9 \pm 23.5 days) significantly higher than the other, through of chi-square test.

\section{Associated Injuries}

One hundred nineteen patients (37\%) sustained a cumulative of 187 associated injuries. Of the patients with associated injuries, 48 (40\%) sustained a head injury, 20 (17\%) suffered a thoracic injury, 15 (13\%) suffered facial injury, 11 (9\%) suffered abdominal injury, 14 (12\%) suffered superior limb fracture, 12 (10\%) suffered inferior limb fracture, and 67 (36\%) suffered others associated lesions. The two most common etiologies of trauma underlying the SCT accompanying these injuries were automobile accidents (61 [51\%] patients), motorcycle accidents (23 [19\%] patients), and accidental falls (16 [13\%] patients) (-Table 1).

\section{Length of Hospital Stay/In-Hospital Complications| Mortality}

The mean duration of hospital stay for all patients who were admitted in our hospital presenting SCT was $11.2 \pm 15.9$ days. Patients who sustained injuries due to gunshot had the longest hospital stay of $31.5 \pm 39.8$ days, compared with other etiologies of trauma ( - Table 1 ). Patients presenting with SCT on the cervical region had the longest hospital stay of $14.3 \pm 20.1$ days, compared with other anatomical regions (-Table 2). Patients presenting with complete motor and sensitive neurologic deficits (ASIA-A) had the longest hospital stay of $21.9 \pm 23.5$ days ( - Table 3 ).

The per-patient in-hospital complication rate was $22 \%$ ( 72 patients), with 37 patients (51\%) presenting with one complication, 25 (35\%) with two complications, and 10 (14\%) 
Table 1 Etiology of trauma and neurologic status/anatomical distribution

\begin{tabular}{|c|c|c|c|c|c|c|c|c|c|c|}
\hline \multirow[t]{2}{*}{ Etiology } & \multirow[t]{2}{*}{ Total } & \multirow[t]{2}{*}{ A } & \multicolumn{2}{|l|}{ ASIA } & \multicolumn{3}{|c|}{$\begin{array}{l}\text { Complic. } \\
(n=117)\end{array}$} & \multicolumn{3}{|c|}{$\begin{array}{l}\text { Injury associate } \\
(n=187)\end{array}$} \\
\hline & & & B, C, D & $\mathrm{E}$ & 01 & 02 & 03 & 01 & 02 & 03 \\
\hline Cars & 133 & 23 & 25 & 85 & 12 & 09 & 01 & 31 & 19 & 11 \\
\hline Motorcycle & 49 & 13 & 13 & 23 & 9 & 03 & 01 & 10 & 07 & 06 \\
\hline Fall & 89 & 14 & 21 & 54 & 11 & 09 & 03 & 12 & 03 & 01 \\
\hline Sports & 21 & 04 & 07 & 10 & 03 & 01 & 01 & 04 & 01 & 0 \\
\hline Diving & 13 & 06 & 05 & 02 & 0 & 03 & 02 & 05 & 0 & 0 \\
\hline Gunshot & 08 & 06 & 01 & 01 & 01 & 0 & 01 & 05 & 02 & 0 \\
\hline Miscellaneous & 08 & 02 & 03 & 03 & 01 & 0 & 01 & 02 & 0 & 0 \\
\hline Total of patients & 321 & 68 & 75 & 178 & 37 & 25 & 10 & 69 & 32 & 18 \\
\hline Total & 321 & 68 & 75 & 178 & 37 & 50 & 30 & 69 & 64 & 54 \\
\hline
\end{tabular}

\begin{tabular}{|c|c|c|c|c|c|c|c|}
\hline Cervical high & \multirow{2}{*}{ Cervical lower } & \multicolumn{6}{|c|}{ Segments } \\
\cline { 3 - 8 } & & Thoracic & Thoracolumbar & Lumbosacral & Two segments & MORT & TI (days) \\
\hline 20 & 58 & 15 & 28 & 03 & 09 & 13 & $9.8( \pm 12.5)$ \\
\hline 01 & 16 & 12 & 12 & 03 & 05 & 0 & $11.8( \pm 13,9)$ \\
\hline 03 & 22 & 07 & 36 & 08 & 13 & 10 & $9.3( \pm 10,2)$ \\
\hline 03 & 13 & 0 & 03 & 01 & 01 & 02 & $17.3( \pm 31.6)$ \\
\hline 0 & 10 & 0 & 0 & 0 & 03 & 0 & $15.5( \pm 22.6)$ \\
\hline 01 & 01 & 04 & 0 & 0 & 02 & 0 & $31.5( \pm 39,8)$ \\
\hline 0 & 01 & 03 & 01 & 01 & 02 & 0 & $7.7( \pm 5.2)$ \\
\hline 28 & 121 & 41 & 80 & 16 & 35 & 25 & $11.2( \pm 15.91)$ \\
\hline 28 & 121 & 41 & 80 & 16 & 35 & 25 & $11.2( \pm 15.91)$ \\
\hline
\end{tabular}

Abbreviations: Complic., complications; HT, hospital time; MORT, mortality.

with three complications. The three most commons complications included pneumonia in 30 patients (42\%), urinary tract infection in 18 patients (25\%), and atelectasis in 6 patients (8\%). Bedsores were notified in three patients (4\%). The etiology of injury most common with complications was automobile accident ( - Table $\mathbf{1}$ ).

The in-hospital mortality rate was $8 \%$ (25 patients). Low cervical region presented the highest risk of in-hospital mortality registering 13 deaths (11\%) between all anatomical distributions of spinal fractures (-Table 2 ). The complete motor and sensitive deficit (ASIA-A) registered 13 deaths (19\%).

\section{Discussion}

SCTs are common occurrences in neurosurgical practice. They account for an important proportion of care, disability, and ethical issues. They can be present in association with other conditions, and its early recognition may be difficult in these cases. The number of patients with spinal trauma has been found to range from 900 to 1,200 per million persons per year. ${ }^{10-12}$ The high rate of complications observed in patients with SCT is due to forces involved in trauma or to the neurologic status of these patients. ${ }^{13}$ The rate of complications have been found to vary between studies. ${ }^{14-17}$

The present study evaluated the presence of associated lesions and the in-hospital clinical complications of patients admitted with SCT treated at a single tertiary institute between January 2008 and June 2012. Our series prospectively evaluated 321 patients suffering from SF, including only those who required specialized investigation and treatment while excluding patients who did not survive the trauma at the time of accident. Thus, our series represents only patients with a real need for posttrauma treatment.

The average age of our patients was 42.68 years, with the majority aged between 20 and 40 years ( - Fig. $\mathbf{1}$ ). In agreement with most published series, we found a high male: female ratio $2.6: 1 .^{18-21}$ The three main etiologies of spine injury found included automobile accidents, accidental falls, and motorcycle accidents. The most affected anatomical region was the low cervical, being C6 the most injury vertebra. The fractures in the cervical are potentially more severe and can result in devastating consequences if treatment is not appropriate. ${ }^{22}$

Twenty-two percent of patients with SCT had some type of clinical complication, the most common being pneumonia, 
Table 2 Anatomical distribution and neurologic status

\begin{tabular}{|c|c|c|c|c|c|c|c|c|c|c|c|c|}
\hline \multirow[t]{2}{*}{ Segments } & \multirow[t]{2}{*}{ Total } & \multirow[t]{2}{*}{ HT (days) } & \multicolumn{3}{|c|}{ ASIA } & \multicolumn{3}{|c|}{ Complications } & \multicolumn{3}{|c|}{$\begin{array}{l}\text { Injury } \\
\text { associated }\end{array}$} & \multirow[t]{2}{*}{ Mortality } \\
\hline & & & A & B, C, D & $E$ & 01 & 02 & 03 & 01 & 02 & 03 & \\
\hline Cervical high (C0-C2) & 28 & $14.3( \pm 22.7)$ & 01 & 02 & 25 & 03 & 03 & 01 & 11 & 02 & 04 & 05 \\
\hline Cervical lower (C3-C7) & 121 & $14.3( \pm 20.1)$ & 36 & 38 & 47 & 14 & 13 & 06 & 24 & 17 & 06 & 13 \\
\hline Thoracic (T1-T10) & 41 & $11.5( \pm 11.5)$ & 17 & 10 & 14 & 07 & 06 & 0 & 08 & 06 & 04 & 03 \\
\hline Thoracolumbar (T11-L2) & 80 & $6.7( \pm 7.3)$ & 05 & 14 & 61 & 11 & 02 & 01 & 14 & 03 & 04 & 02 \\
\hline Lumbosacral (L3-S1) & 16 & $3.8( \pm 3.2)$ & 0 & 03 & 13 & 01 & 0 & 0 & 01 & 02 & 0 & 0 \\
\hline Two segments injury & 35 & $10.9( \pm 12.3)$ & 09 & 08 & 18 & 01 & 01 & 02 & 11 & 02 & 0 & 02 \\
\hline Total DE patients & 321 & $11.2( \pm 15.9)$ & 68 & 75 & 178 & 37 & 25 & 10 & 69 & 32 & 18 & 25 \\
\hline Accurate Total & 356 & $11.2( \pm 15.9)$ & 68 & 75 & 178 & 37 & 50 & 30 & 69 & 64 & 54 & 25 \\
\hline
\end{tabular}

Abbreviations: HT, hospital time.
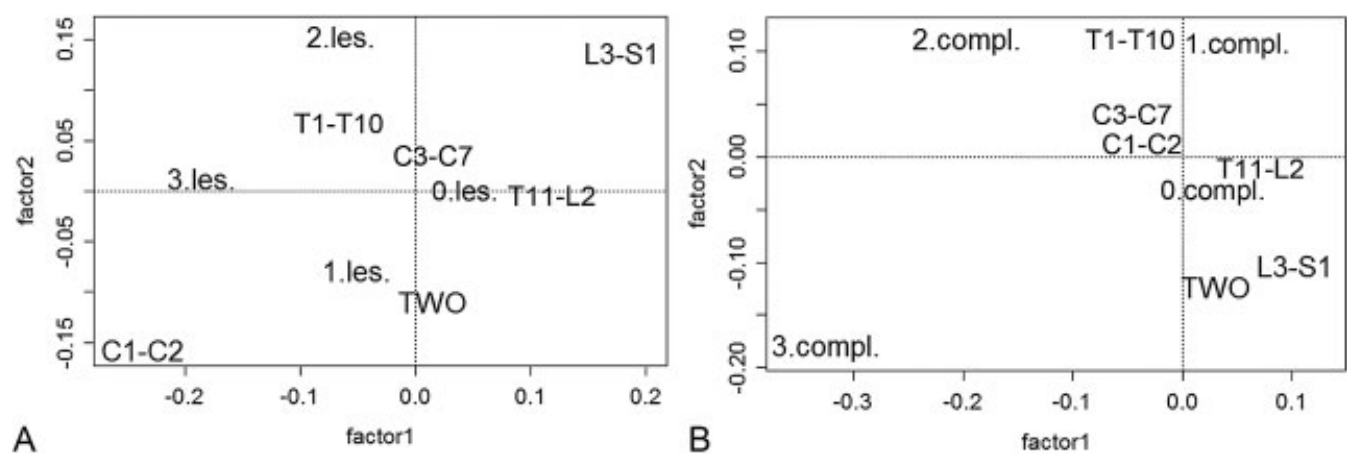

Fig. 2 (A) Anatomical distribution of the spinal cord injury and the number of associated injuries (chi-square test, $p=0.001$ ). (B) Anatomical distribution of the associated lesions and number of complications (chi-square test, $p<0.001$ ).

observed in $42 \%$ of patients with complications. Of patients with complete motor and sensitive deficit (ASIA-A), 54\% presented with any clinical complication during hospital stay (-Table 3). These results suggest that those who lose the ability to walk were at higher risk for developing any clinical complication. According to Santos et al, ${ }^{15}$ this is particularly true to infections of the respiratory tract. Our study showed a statistically significant association between the neurologic status of patients with SCT and the number of complications, demonstrating that those with worst injuries usually present with a higher number of clinical complications.

The study of anatomical segment of SCT also revealed a higher occurrence of clinical complications, worst neurologic status, and death between patients with low cervical spine injury (-Table 2). Twenty-seven percent of patients with low cervical spine injury had some clinical complication, 30\% presented on admission as ASIA-A, and 11\% died. According to Kawu et $\mathrm{al}^{16}$ the risk factors associated with mortality following spine cord injury were age, Glasgow Coma Scale inferior of nine, cervical spine injury, and complete neurologic injury and those for clinical complications were cervical spine injury and ASIA-A. Our study showed statistically that patients with higher levels of SCT along the spine present with more associated lesions and clinical complications during in-hospital care.

Associated lesions were identified in $37 \%$ of patients sustaining a cumulative of 187 associated injuries. The

Table 3 Neurologic status and associated lesions/complications

\begin{tabular}{|c|c|c|c|c|c|c|c|c|c|}
\hline \multirow[t]{2}{*}{ ASIA } & \multirow[t]{2}{*}{ Total } & \multirow[t]{2}{*}{ Average length of hospitalization (days) } & \multicolumn{3}{|c|}{ Complications } & \multicolumn{3}{|c|}{ Injury associated } & \multirow[t]{2}{*}{ Mortality } \\
\hline & & & 1 & 2 & 3 & 1 & 2 & 3 & \\
\hline$A$ & 68 & $21.9( \pm 23.5)^{a}$ & 15 & 14 & 8 & 18 & 7 & 3 & 13 \\
\hline B, C, D & 75 & $9.8( \pm 12)^{\mathrm{b}}$ & 7 & 7 & 0 & 14 & 8 & 2 & 6 \\
\hline$E$ & 178 & $7.6( \pm 11.5)^{c}$ & 15 & 4 & 2 & 37 & 17 & 13 & 6 \\
\hline Total & 321 & $11.2( \pm 15.9)$ & 37 & 25 & 10 & 69 & 32 & 18 & 25 \\
\hline
\end{tabular}

\footnotetext{
a,b,c Statistical difference of $p<0.05$ by Dunn test.
} 


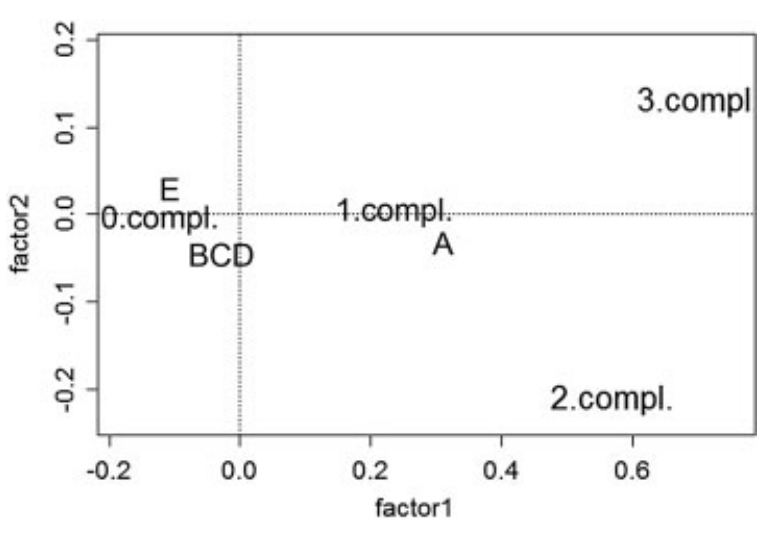

Fig. 3 Neurologic status and clinical complications (chi-square test, $p<0.001)$.

most common was head trauma, which represented $40 \%$ of all associated injuries. According to Holly et $\mathrm{al}^{7}$ and Lourenco et al, ${ }^{23}$ because of the etiology and mechanisms of trauma in the cervical region, the head and the chest are at great risk of associated injuries.

\section{Conclusion}

The SCT was more common in men, but women older than 50 years presented with a higher risk than men of the same age. Automobile accidents, motorcycle accidents, and gunshots resulted in more injuries associated. The cervical spine involvement was directly related to an increase in the number of associated injuries, complications, and mortality. Already, the neurologic status ASIA-A was associated with an increase in the number of complications, length of stay, and mortality. We conclude that the predictive factors of prognosis in these patients included age, sex, cause of injury, anatomic distribution, and neurologic status.

\section{Note}

This study is part of the dissertation Morais DF carried out at FAMERP, São José do Rio Preto, São Paulo, Brazil.

\section{References}

1 Oliver M, Inaba K, Tang A, et al. The changing epidemiology of spinal trauma: a 13-year review from a level I trauma centre. Injury 2012;43(8):1296-1300

2 Cunha MLV, da Cunha MLV, Veríssimo DCA, Rehder R, Borba LAB. Epidemiological study of spine fractures at a referral center for spinal disease in Parana. Arq Bras Neurocir. 2012;31(4):179-183

3 Dajpratham P, Kongkasuwan R. Quality of life among the traumatic spinal cord injured patients. J Med Assoc Thai 2011;94(10): 1252-1259

4 Morais DF, de Melo Neto JS, Spotti AR, Meguins LC, Mussi SE, Tognola WA. Image diagnosis of patients submitted to spinal injury. J Bras Neurocir. 2013;24:33-39
5 Morais DF, de Melo Neto JS, Meguins LC, Mussi SE, Ferraz Filho JRL, Tognola WA. Clinical applicability of magnetic resonance imaging in acute spinal cord trauma. Eur Spine J 2014;23(7):1457-1463

6 Wang H, Zhang Y, Xiang Q et al. Epidemiology of traumatic spinal fractures: experience from medical university-affiliated hospitals in Chongqing, China, 2001-2010. J Neurosurg Spine 2012;17(5): 459-468

7 Holly LT, Kelly DF, Counelis GJ, Blinman T, McArthur DL, Cryer HG. Cervical spine trauma associated with moderate and severe head injury: incidence, risk factors, and injury characteristics. J Neurosurg 2002;96(3, Suppl):285-291

8 Paiva WS, Oliveira AM, Andrade AF, Amorim RL, Lourenço LJ, Teixeira MJ. Spinal cord injury and its association with blunt head trauma. Int J Gen Med 2011;4:613-615

9 Ditunno JF Jr, Young W, Donovan WH, Creasey G; American Spinal Injury Association. The international standards booklet for neurological and functional classification of spinal cord injury. Paraplegia 1994;32(2):70-80

10 Knútsdóttir $\mathrm{S}$, Thórisdóttir $\mathrm{H}$, Sigvaldason $\mathrm{K}$, Jónsson $\mathrm{H} \mathrm{Jr}$, Björnsson A, Ingvarsson P. Epidemiology of traumatic spinal cord injuries in Iceland from 1975 to 2009. Spinal Cord 2012; 50(2):123-126

11 Van Den Berg M, Castellote JM, Mahillo-Fernandez I, de PedroCuesta J. Incidence of traumatic spinal cord injury in Aragón, Spain (1972-2008). J Neurotrauma 2011;28(3):469-477

12 Hagen EM, Eide GE, Rekand T, Gilhus NE, Gronning M. A 50-year follow-up of the incidence of traumatic spinal cord injuries in Western Norway. Spinal Cord 2010;48(4):313-318

13 Rhee P, Kuncir EJ, Johnson L, et al. Cervical spine injury is highly dependent on the mechanism of injury following blunt and penetrating assault. J Trauma 2006;61(5):1166-1170

14 Aarabi B, Harrop JS, Tator CH, et al. Predictors of pulmonary complications in blunt traumatic spinal cord injury. J Neurosurg Spine 2012;17(1, Suppl):38-45

15 Santos EA, Santos Filho WJ, Possatti LL, Bittencourt LR, Fontoura EA, Botelho RV. Clinical complications in patients with severe cervical spinal trauma: a ten-year prospective study. Arq Neuropsiquiatr 2012;70(7):524-528

16 Kawu AA, Alimi FM, Gbadegesin AA, et al. Complications and causes of death in spinal cord injury patients in Nigeria. West Afr J Med 2011;30(4):301-304

17 Tollefsen E, Fondenes O. Respiratory complications associated with spinal cord injury. Tidsskr Nor Laegeforen 2012;132(9): 1111-1114

18 Schoenfeld AJ, McCriskin B, Hsiao M, Burks R. Incidence and epidemiology of spinal cord injury within a closed American population: the United States military (2000-2009). Spinal Cord 2011;49(8):874-879

19 Ning GZ, Wu Q Li YL, Feng SQ. Epidemiology of traumatic spinal cord injury in Asia: a systematic review. J Spinal Cord Med 2012; 35(4):229-239

20 Ibrahim A, Lee KY, Kanoo LL, et al. Epidemiology of spinal cord injury in Hospital Kuala Lumpur. Spine 2013;38(5):419-424

21 Morais DF, Spotti AR, Cohen MI, Mussi SE, de Melo Neto JS, Tognola WA. Perfil epidemiológico de pacientes com traumatismo raquimedular atendidos em hospital terciário. Coluna/Columna 2013; 12(2):149-152

22 Marcon RM, Cristante AF, Teixeira WJ, Narasaki DK, Oliveira RP, de Barros Filho TE. Fractures of the cervical spine. Clinics (Sao Paulo) 2013;68(11):1455-1461

23 Lourenco LJO, Alves EM, Andrade AF. Spine injuries and severe or moderate traumatic head injuries. Coluna/Columna. 2008;7(2): 143-145 